\title{
Modern spectral climate patterns in rhythmically deposited argillites of the Gowganda Formation (Early Proterozoic), southern Ontario, Canada
}

\author{
Gary B. Hughes ${ }^{\mathrm{a}}$, Robert Giegengack ${ }^{\mathrm{b}}$, Haralambos N. Kritikos ${ }^{\mathrm{c}}$ \\ a Raytheon Vision Systems, 75 Coromar Drive B03/66, Goleta, CA 93117, USA \\ b Department of Earth and Environmental Science, University of Pennsylvania, Philadelphia, PA 19104, USA \\ c Department of Electrical Engineering, University of Pennsylvania, Philadelphia, PA 19104, USA
}

\begin{abstract}
Rhythmically deposited argillites of the Gowganda Formation (ca. 2.0-2.5 Ga) probably formed in a glacial setting. Drop stones and layered sedimentary couplets in the rock presumably indicate formation in a lacustrine environment with repeating freeze-thaw cycles. It is plausible that temporal variations in the thickness of sedimentary layers are related to interannual climatic variability, e.g. average seasonal temperature could have influenced melting and the amount of sediment source material carried to the lake. A sequence of layer couplet thickness measurements was made from high-resolution digitized photographs taken at an outcrop in southern Ontario, Canada. The frequency spectrum of thickness measurements displays patterns that resemble some aspects of modern climate. Coherent periodic modes in the thickness spectrum appear at 9.9-10.7 layer couplets and at 14.3 layer couplets. It is unlikely that these coherent modes result from random processes. Modern instrument records of regional temperature and rainfall display similar spectral patterns, with some datasets showing significant modes near $14 \mathrm{yr}$ in both parameters. Rainfall and temperature could have affected sedimentary layering in the Gowganda argillite sequence, and climate modulation of couplet thickness emerges as the most likely explanation of the observed layering pattern. If this interpretation is correct, the layer couplets represent predominantly annual accumulations of sediment (i.e. they are varves), and the thickness spectrum provides a glimpse of Early Proterozoic climatic variability. The presence of interannual climate patterns is not unanticipated, but field evidence presented here may be of some value in developing a climate theory for the Early Proterozoic.
\end{abstract}

Keywords: varves; paleoclimate; Gowganda Formation; spectral analysis

\section{Introduction}

Rhythmically stratified argillites have been described in the Huronian Cobalt Series, Gowganda Formation (Early Proterozoic) in southern Ontario, Canada [1-7]. The sediments that comprise 
these rocks were deposited ca. 2.0-2.5 Ga ago [8]. Alternating layers in the rock are defined by bands of distinct texture and color. In cross-section, the lighter member of each such layer couplet is nearly homogeneous in texture, being comprised of predominantly clay-sized clasts. The darker member of each layer couplet contains sand and silt mixed with clay-sized particles.

One layered argillite outcrop in southern Ontario is situated in close proximity to rocks that have been interpreted as glacial tills [8]. At this outcrop, numerous drop stones are present within the sedimentary layers. These and other field observations have been cited as evidence that the argillite sediments were deposited in a near-glacial lacustrine setting [1,2,9-11]. Drop stones were likely rafted by floating ice to the interior of a glacial-margin lake where the sediments were being deposited, and were released to sink to the lake floor as the floating ice melted. Alternating intervals of ice-covered and open water, as would occur in regular freeze-thaw cycles, presumably produced the series of superposed layer couplets.

If layering in the Gowganda argillite sediments was produced by a regular freeze-thaw cycle, then local climate during the time that the sediments were being deposited may have affected the content, texture, and/or thickness of individual layers. In modern analogs of the presumed glacial-margin lake setting, bottom sediments are predominantly glaciogenic, i.e. most of the sediment source material is carried to the site of deposition by glacial melt-water runoff. Local or regional climate patterns may influence melting and total runoff for any sedimentary cycle. Warm or rainy episodes produce more runoff than do cool or dry episodes. Relatively high runoff in a given cycle carries more sediment source material to the lake, producing a relatively thicker layer couplet than would low runoff in another cycle. Interannual climate variability acts to modulate layer couplet thickness in modern glacial-lake environments, and could have acted in a similar way in the past. This connection is speculative, but, if climate affected layer couplet formation, then cyclic modes in the thickness frequency power spectrum may reflect variability in those aspects of climate that influenced layer couplet thickness. This study explores the hypothesis that sedimentary layering in the Gowganda argillites was produced by annual climate cycles.

\section{Field and laboratory observations}

The Gowganda Formation consists of metamorphosed sedimentary rock, including brecciated granite diamictite and sections of rhythmically laminated argillites. The diamictites are typically boulder conglomerates which were likely formed as lodgment till under glaciers [8]. Several outcrops of argillite appear in the Elliot Lake area in close proximity to Gowganda boulder conglomerates. At one outcrop in the Mississagi River Valley near Wharncliffe (at the intersection of highway 554 and highway $129,46.413^{\circ} \mathrm{N}$, $83.325^{\circ} \mathrm{W}$ ), approximately $15 \mathrm{~m}$ of Cobalt Series laminar argillite are exposed in a cliff face (Fig. 1). The sequence extends into the ground at the base of the cliff. At least 750 individual sedimentary layer couplets are exposed at the outcrop, with an unknown number below ground. The basal and lateral boundaries of the argillite section are obscured by soil and debris that have fallen from the cliff, so we do not know if they were deposited on top of, adjacent to, or under a conglomerate.

The Wharncliffe argillite is mainly comprised of clay- to sand-sized silica clasts that have been cemented together in a calcium carbonate matrix. A magnified cross-section of a rock extracted from the cliff shows alternating light and dark argillite layers, and a granitic drop stone (Fig. 2). Light layers contain predominantly clay-sized clasts and display a fining-upward sequence within each layer. Dark layers generally consist of clay-sized particles mixed with coarser clasts (sand and silt). Drop stones of granitic composition are common in the outcrop. Most are situated at the boundary between a light layer below and a dark layer above. Drop stones are sometimes located completely embedded within a dark layer, but none were found embedded within a light layer.

Elemental analysis of the layers was performed by energy-dispersive spectroscopy (EDS) in a scanning electron microscope. Successive measurements were made at $1.00 \mathrm{~mm}$ spacing through 


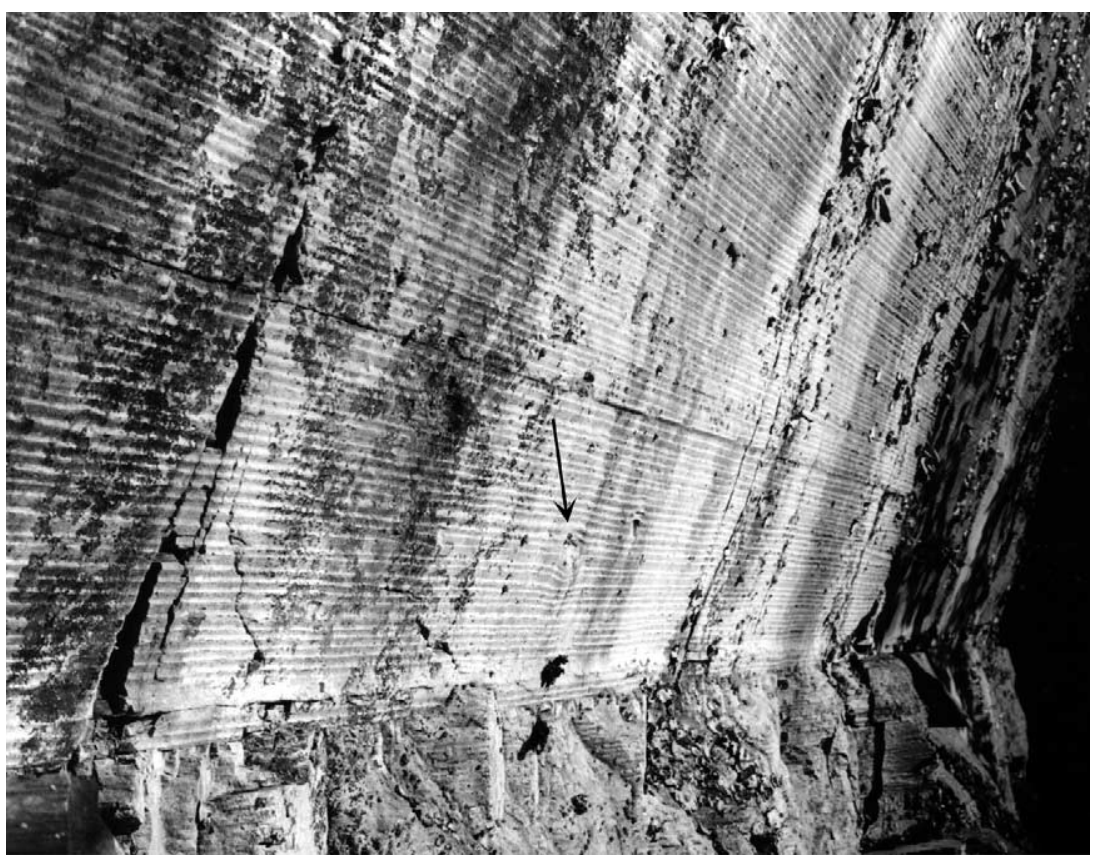

Fig. 1. Cobalt Series laminar argillite (Early Proterozoic Gowganda Formation) exposed at an outcrop in southern Ontario, Canada $\left(46.413^{\circ} \mathrm{N}, 83.325^{\circ} \mathrm{W}\right)$. Ridges in the weathered surface correspond to coarser members of sedimentary couplets presumably produced by annual freeze-thaw cycles in a glacial-margin lake. Average couplet thickness in this section is $9.92 \mathrm{~mm}$, ranging from 5.01 to $23.34 \mathrm{~mm}$. A large drop stone is noticeable in the center of the photo.

a vertical sequence of four layers (two complete layer couplets). Significant differences in average elemental proportions were noted between light and dark layers. Higher relative amounts of potassium with respect to calcium occur in light layers. This may be interpreted to indicate a higher concentration of clay minerals in the light layers than in the coarser-grained sediment of dark layers.

These field and laboratory observations support the presumed deposition of the sediment in an environment with regular freeze-thaw episodes. Light layers represent winter deposition as smaller clasts settled out of the still water of an ice-covered glacial-margin lake. Darker layers represent summer deposition of coarser-grained sediments in an open body of water receiving glacial runoff. This pattern of sedimentary layer couplets is observed in sediments from modern boreal lakes with annual freeze-thaw cycles [12].

To assess variability in layer couplet thickness in the Wharncliffe argillite, a continuous $2.54 \mathrm{~m}$ section of the outcrop, containing 256 distinguishable layer couplets, was chosen for this study. A sequence of close-up photographs of the study section was taken at the outcrop. The camera was mounted on a tripod to maintain a constant distance from the surface and to orient the plane of the film parallel to the cliff face. All camera settings were held constant throughout the sequence. Two vertical photo sequences spanning the study section were taken within a horizontal range of $1 \mathrm{~m}$. The photographs depict a weathered surface with a consistent pattern of differential weathering determined by substrate texture. The dark, coarser layers correspond to ridges in the weathered surface. Based on relationships observed in cross-sections and in measurements of elemental ratios within the layers, characteristics of the weathering pattern were used to establish layer couplet boundaries in the photographs. The photo sequences were digitized by scanning at 236 pixels per $\mathrm{cm}$, giving a pixel resolution of 0.004 $\mathrm{cm}$ per pixel. Layer couplet thicknesses were mea- 


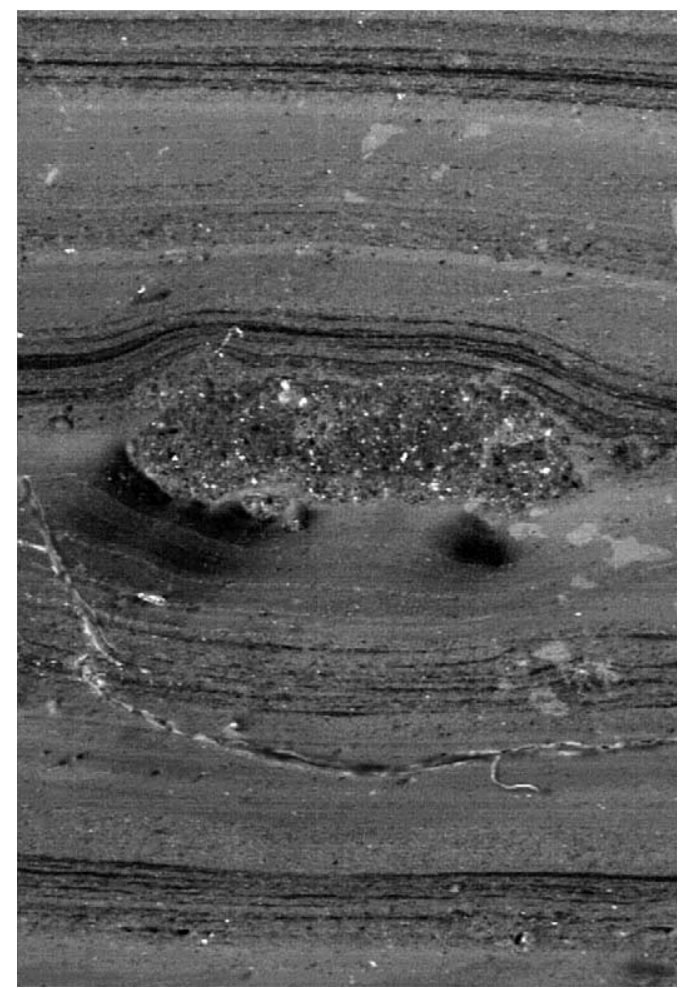

Fig. 2. Cross-section of a Gowganda argillite from the Wharncliffe outcrop showing alternating light and dark layers, and a granitic drop stone. Light layers contain predominantly clay-sized clasts, and presumably represent winter deposition in an ice-covered lake. Darker layers contain silt and sand mixed with clay-sized particles, and presumably represent summer deposition in an open body of water. Drop stones were probably rafted to the center of the lake by floating ice.

sured in the digitized images as the distance between the pixel boundaries of successive transitions from dark layer below to light layer above. Each layer couplet was measured five times at distinct locations in each of the digital photo sequences. The average of the 10 measurements for each couplet was taken to represent the actual couplet thickness. The thickness of 256 consecutive couplets was determined. The 256-measurement mean was subtracted from each individual value to produce a time series of deviations about the mean couplet thickness (Fig. 3). In the portion of the outcrop containing the 256 measured couplets, the couplet thickness averages $9.92 \mathrm{~mm}$ and ranges from 5.0 to $23.3 \mathrm{~mm}$.

\section{Spectral methods and results}

The discrete Fourier transform (DFT) periodogram spectrum of the couplet thickness sequence was computed, giving spectral amplitude at 128 discrete basis frequencies in the Nyquist range, corresponding to periods between 2 and 256 couplets, inclusive (Fig. 4A). As in previous studies utilizing DFT-derived spectra, significant modes are not readily apparent in the spectral profile [2]. Several issues combine to dilute the spectral results computed by DFT. First, the discretization error is large, due to low precision in the measured data. Furthermore, with only 256 data values, the DFT frequency bins contain power averaged over a wide range of frequencies (bin width is 0.0039 cycles per couplet). Finally, the basis frequencies of the DFT do not necessarily occur at points of maximum spectral power in the dataset, and the DFT leaks power to adjacent frequency bins. This results in underestimation of power that lies in narrow frequency bands not centered on a DFT basis frequency.

The spectrum was also computed by maximum entropy method (MEM), which allows determination of spectral amplitude at arbitrary frequencies within the Nyquist range (Fig. 4B). The MEM algorithm is better suited than DFT for detection of narrow spectral peaks. The MEM coefficients

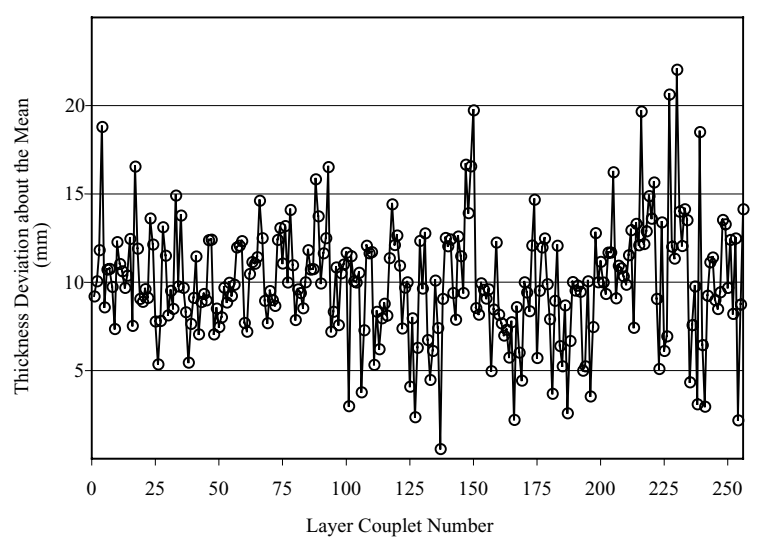

Fig. 3. Continuous sequence of layer couplet thicknesses, as deviations about the mean layer couplet thickness. A layer couplet was defined to be the distance between boundaries of successive transitions from dark layer below to light layer above. 

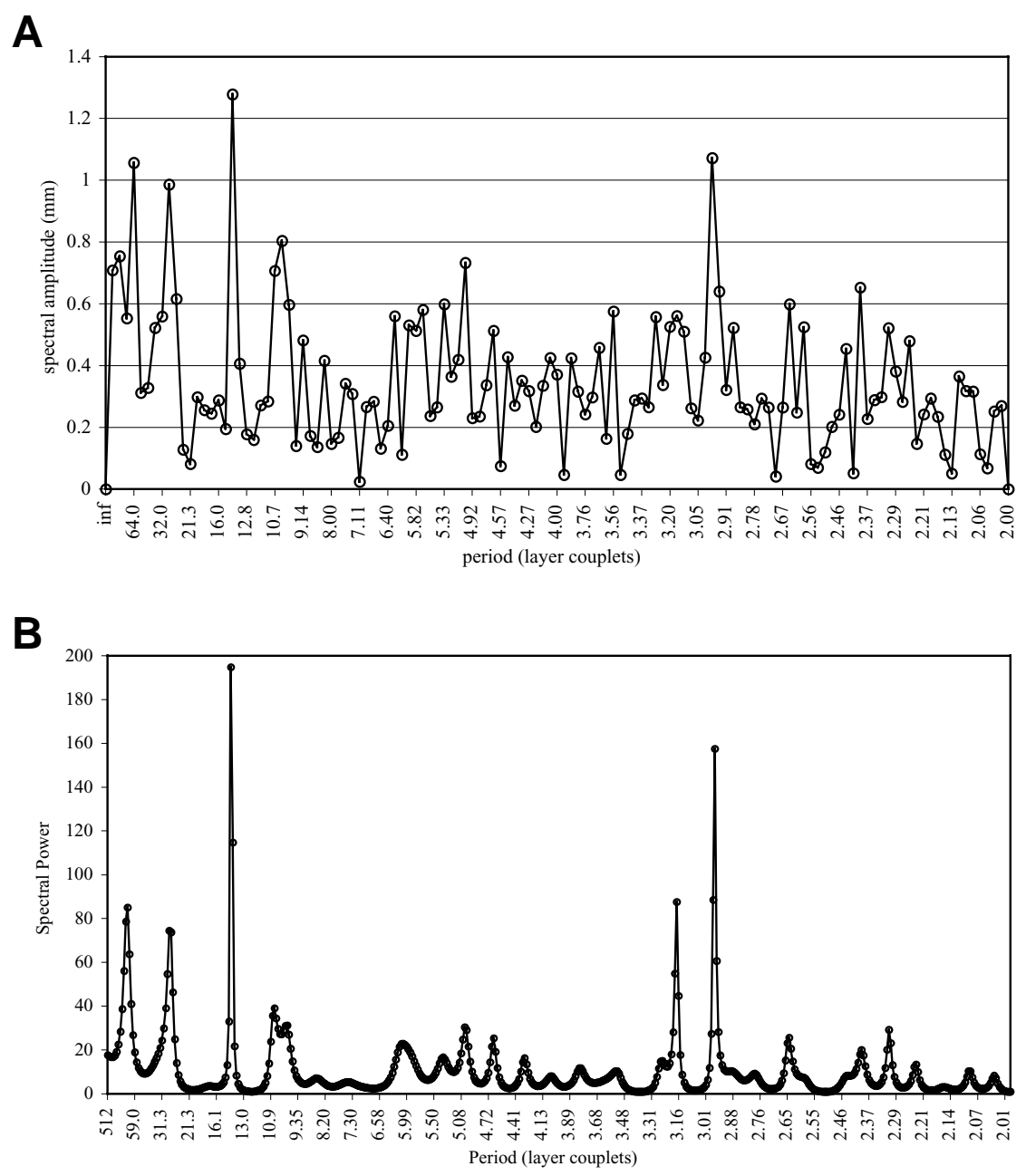

Fig. 4. (A) DFT and (B) MEM spectra of thickness measurements from the Wharncliffe argillite couplet thickness sequence.

were computed with 256 data values and 70 poles. Spectral power was determined from the MEM coefficients at 500 equally spaced frequencies in the Nyquist range between periods of 512 and 2 layer couplets. However, the use of MEM for spectral power estimates is often risky. Stochastic fluctuations can sometimes give rise to short-lived, strongly periodic signals that produce 'spurious' peaks in the MEM spectrum. Furthermore, the profile of the MEM spectrum is sensitive to the number of poles used, as well as to the choice of frequencies where spectral power is evaluated.
The statistical significance associated with peaks in the MEM spectrum is no greater than the significance associated with the peaks in the DFT spectrum.

The confidence associated with spectral peaks can be enhanced by examining the persistence of the peak over the time span of the data. Spectral power in both DFT and MEM profiles represents average power values at a particular frequency over the time span of the data. In particular, peaks in the spectral profiles may arise from 'quasi-periodic' phenomena that are strongly periodic 

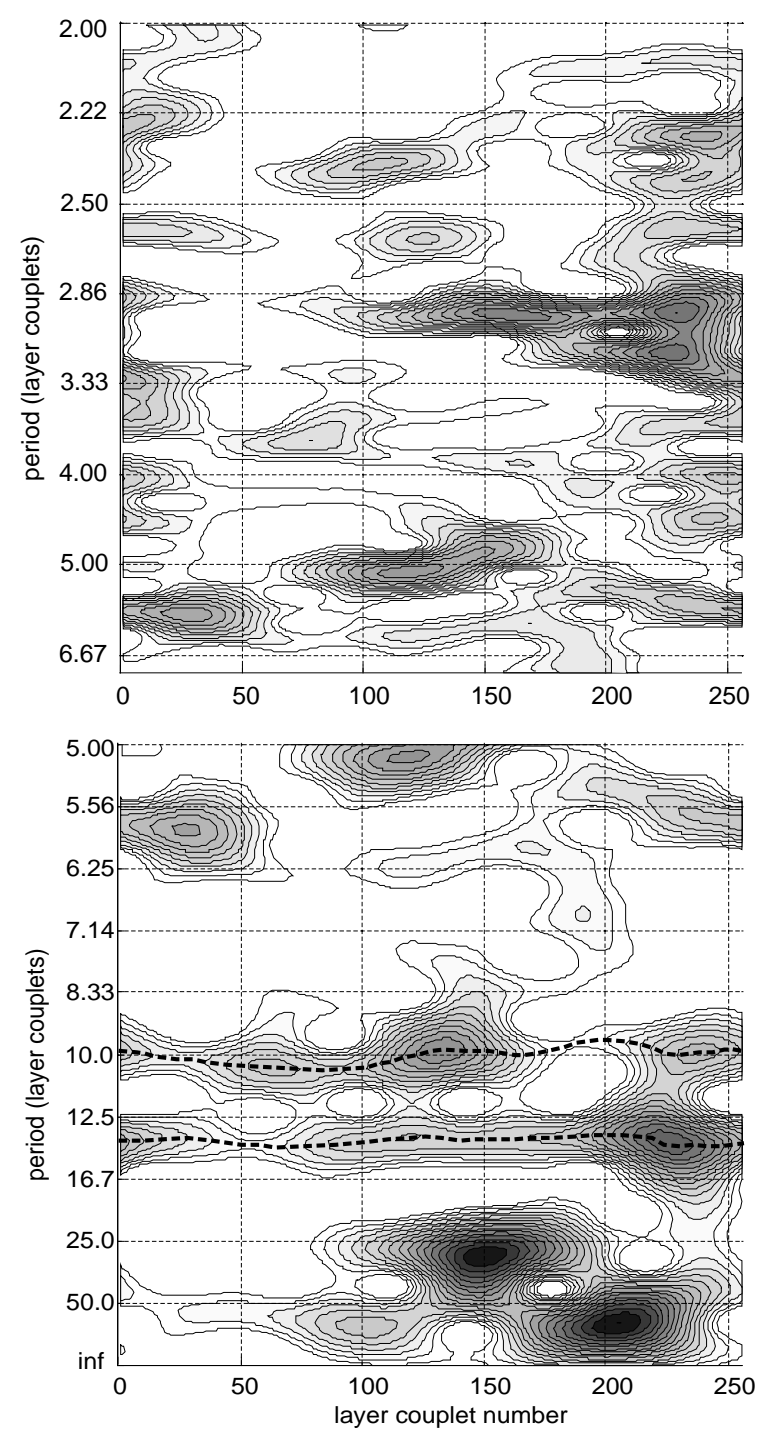

Fig. 5. CSA of Wharncliffe couplet thickness sequence showing variations in spectral composition over time. Darker values represent higher spectral power. At least two of the spectral peaks are consistently present over the time span of the measured column, near a period of 10.0 layer couplets, and again near a period of 14.3 layer couplets.

but short-lived (this is a common attribute of many climate parameters). To investigate variations in the spectral profile over time, a coherent state analysis (CSA) [13] with a window of 20 layer couplets was computed for the couplet thickness sequence (Fig. 5). At least two of the peaks in the MEM and DFT spectra appear as coherent modes throughout the dataset. These modes occur near a period of 9.9-10.7 layer couplets and again near a period of 14.3 layer couplets. Most of the other spectral peaks arise from phenomena that were short-lived and strongly periodic, but non-coherent over the span of the data. It may not be possible to distinguish any of these peaks from white noise with high statistical confidence. However, it is highly unlikely that the coherent modes at 9.9-10.7 and 14.3 layer couplets result from random processes.

\section{Spectral interpretation}

Patterns in the couplet thickness sequence were probably forced by variability of environmental conditions present at the time of deposition. Climate forcing is one sound hypothesis for explaining the deposition pattern. The largest peak in the argillite thickness spectrum occurs as a coherent mode at a period of 14.3 layer couplets. Similar peaks have been identified in the modern instrument record of regional temperature and rainfall time series. Spectral analyses of the central England temperature time series have identified prominent periodicities at $14.2 \mathrm{yr}$ [14] and $15 \mathrm{yr}$ [15]. Historical rainfall records in the Los Angeles Basin (California) show a strong spectral peak at $18.2 \mathrm{yr}$, with the spectrum of runoff showing broad power between 10.4 and 27.3 yr [16]. The spectra of rainfall and runoff given in [16] correlate well with the spectrum of sediment density in the Santa Monica Basin. The peak in the argillite thickness spectrum at 27.8 layer couplets is also in good agreement with these two studies, even though it is not coherent throughout the argillite data sequence. Both rainfall and temperature could have affected couplet thickness in the argillite sequence by modulating melt-water input.

The peaks at 10.7 and 9.9 layer couplets are associated with a single coherent mode in the thickness spectrum. The structure of this mode is consistent with modern variability in the period of the sunspot cycle observed in historical records [17]. The solar cycle could plausibly affect sedimentary layering indirectly by modulating climate 
parameters such as temperature $[18,19]$ and rainfall [20] at interannual time scales. Indirect expressions of the solar cycle have also been identified in modern sediments [21,22], and possibly in Eocene [23] and other Proterozoic sediments [24].

Other spectral peaks in the argillite thickness spectrum may hold less statistical significance, since they are not coherent throughout the sequence. However, these 'quasi-periodic' signals are also seen in modern climate parameters $[15,23,25,26]$ and may be an intrinsic feature of climate variability. In this context, it is at least plausible to speculate on possible climate forcing associated with other peaks. The argillite thickness spectrum displays minor peaks at 2.97 and 3.17 layer couplets. These peaks do not persist, but are rather short-lived. Variability in this frequency range is similar to the Quasi Triennial Oscillation (QTO) in [27], which identified theoretical models for 33 tones in the spectrum of atmospheric pressure with periods between 2 and 70 months based on estimates of solar flux. There is also a non-coherent peak in the argillite spectrum at 6.10 layer couplets. A peak in the spectrum of atmospheric pressure at $6.24 \mathrm{yr}$ is predicted [27] due to non-linear interactions between the annual cycle and the Atmospheric Pole Tide (APT). Although variations in atmospheric pressure may not have a direct influence on sedimentary layer thickness, atmospheric pressure modes are forced by variations in solar flux, which could also influence layer thickness by influencing melting.

Several small, non-coherent peaks in the argillite thickness spectra appear between 4 and 5 layer couplets. This pattern resembles interannual, broad-band spectral patterns observed in regional climate systems such as El Niño-Southern Oscillation (ENSO) and the North Atlantic Oscillation (NAO). In the modern record, sporadic power in the NAO index spectrum is observed at periods between 5 and $7 \mathrm{yr}$ [28]. The same study also reported power in the NAO index spectrum at 80-90 yr, beginning around 1850, with comparable variability in temperature records. Geologic archives have also produced some evidence of ENSO-like variability at longer periods, e.g. ENSO variability was identified in the thickness spectrum of Eocene sedimentary layers [23]. The argillite thickness spectrum shows some non-coherent power at 77.2 layer couplets.

At the present time, it is not possible to determine from field evidence what the period of deposition for each couplet was, because we cannot establish the time span over which the sediment column was deposited. If the depositional setting was indeed a peri-glacial lake, then the layer couplets may represent annual accumulations of sediment. Sediment characteristics in modern boreal and high-altitude lakes reinforce this assessment. However, study of the modern record reveals patterns that advise caution in interpreting the Gowganda couplets as annual accumulations. Deposition of turbidites can confound a predominantly annual sequence by adding non-existent 'years'. Furthermore, the depositional rhythm may be altered during prolonged cold or warm periods, precluding the formation of a couplet member where one or more distinct layers would have been deposited under different conditions. It is also possible that ice cover melted only in the warmest years or that the lake was covered with ice only in the coldest years. These freeze-thaw scenarios would create cyclic deposition patterns with periods greater than $1 \mathrm{yr}$. The cyclic period may also have been irregular, where couplet formation was driven by prolonged cold periods (or warm periods) with unevenly spaced warmings (or coolings).

Since it is possible that the sequence of couplet thickness measurements does not represent strictly annual layering, it is appropriate to address what effects missing layers might have on the frequency spectrum of thicknesses. In the case where each couplet represented $2 \mathrm{yr}$ of deposition instead of 1 , the spectrum would be identical, but temporal periods corresponding to couplet periods would all be doubled, e.g. the peak at 2.97 layer couplets would represent a temporal period of $5.94 \mathrm{yr}$, etc. A more likely scenario would be the absence of single layers every few cycles, caused by cold years lacking a summer thaw. In the case where a missing cycle occurred on average once every $10 \mathrm{yr}$, the thickness spectrum would still have a similar shape, but it would be stretched temporally by a factor of 1.1. The association of spectral peaks with climate phenomena discussed above is not 
significantly altered by allowing for missing layers even as often as every $5 \mathrm{yr}$.

Random addition to the argillite sequence of turbidite layers would have the opposite effect on the spectral profile, i.e. a shrinking of the spectrum above the frequency domain without significant changes in the profile. More radical scenarios would have larger effects on the spectral profile. However, depositional rhythms radically different from an annual or other constant time-increment cycle would present difficulties for explaining the observed regularity of layering. In the presumed glacial-margin lake setting, a freeze-thaw cycle with a regular and sustained sub-annual period is considered unlikely due to lack of a plausible forcing mechanism.

\section{Discussion}

The physical characteristics of the Elliot Lake sequence and the analogous formation of modern glacial-lake varves support the interpretations of a glacial setting and repeated, predominantly annual, freeze-thaw cycles. The spectral profile derived from couplet thickness measurements is robust to moderate perturbations in depositional mechanism, preserving climatic interpretations of spectral peaks over a range of assumptions about the period of couplet formation. The spectral profile is most easily explained under the assumptions of predominantly annual couplet formation and climate forcing of layer couplet thickness. The argillite thickness spectrum indicates that at least some aspects of Early Proterozoic paleoclimate variability were similar to those of the present climate.

Climate forcing of couplet thickness is plausible, but other explanations could be proposed to account for the observed patterns in the thickness sequence. In the presumed periglacial-lake setting, it seems improbable that tidal forces would have significant effects on sediment layering. Furthermore, the spectrum of tidally forced layer thickness measurements would display a primary tone with a series of harmonics. Other mechanical scenarios devoid of climate interaction are unlikely to have produced the observed spectral pattern.

Additional analyses may also add new and in- teresting dimensions to the investigation of the dataset. If each layer in a couplet represents a different season, then it may be interesting to consider a separate sequence of layer thicknesses for each couplet layer. The contribution of each 'season' to variability in the annual signal could be investigated by measuring the layers individually, possibly providing sub-annual resolution. It may also be interesting to investigate the effects of the opposite 'coupling' on the overall spectrum. For the current study, a couplet was defined as the combination of one dark layer below and one light layer above, a 'summer+following winter' combination. This association was based on the assumption that at least some of the material deposited during the winter season was transported to the lake during the summer, but was suspended in the water column by turbulence until the freeze-over. The couplet thickness sequence would be slightly different by making the opposite association (one light layer below and one dark layer above, a 'winter+following summer' combination).

This study utilized DFT, MEM and CSA methods to investigate the spectral composition of the dataset. It may also be interesting to employ other spectral estimation tools with the dataset. The local wavelet spectrum, e.g. as presented in [28], could be compared to the Fourier-basis representation produced by CSA in Fig. 5. Empirical orthogonal functions (EOFs), e.g. as presented in [14], could be computed and compared with multiple-taper spectral analysis methods (MTM) [29], e.g. as presented in [25], to experiment with whitenoise and quasi-periodic noise characterization and signal detection.

The presence of patterns in Early Proterozoic interannual climate variability is not surprising. The documentation of such variability based on field data could help to better define a climate theory for the period of deposition of these sediments. Further study, including drill cores at the Wharncliffe outcrop and other rhythmite sequences in the Cobalt Series, is warranted. A modern dataset from a known annually laminated sediment sequence deposited in a glacial-margin lake where the local weather has been monitored for a significant period of time would also serve to test 
the forcing hypotheses developed here to explain the layering pattern observed in the Gowganda varve sequence.

\section{Acknowledgements}

Funding for energy-dispersive spectroscopic analysis reported here was provided by the Mellon Foundation and is gratefully acknowledged. The authors gratefully acknowledge the contributions of Jerry Harrison, University of Pennsylvania School of Dental Medicine, for assistance with energy-dispersive spectroscopic analysis. The authors also recognize the generous contributions of R. Ian Harker, whose previous work at the outcrop and enthusiasm for continued study of these varves provided the encouragement to undertake this study. The authors also wish to acknowledge the astute observations of the two anonymous reviewers, whose comments contributed to key improvements in the final version of this paper. [BOYLE]

\section{References}

[1] P.E. Schenk, Depositional environment of the Gowganda Formation (Precambrian) at the south end of Lake Timagami, Ontario, J. Sediment. Petrol. 35 (1965) 309318.

[2] T. Jackson, Power-spectrum analysis of two 'varved' argillites in the Huronian Cobalt Series (Precambrian) of Canada, J. Sediment. Petrol. 35 (1965) 877-886.

[3] G.M. Young, Geochemistry of Early Proterozoic tillites and argillites of the Gowganda Formation, Ontario, Canada, Geochim. Cosmochim. Acta 33 (1969) 483-492.

[4] M.J. Frarey, Geology of the Huronian Belt between Sault Ste. Marie and Blind River, Ontario, Geological Survey of Canada Memoir 383, 1977.

[5] A.D. Miall, Glaciomarine sedimentation in Gowganda Formation (Huronian), Northern Ontario, J. Sediment. Petrol. 53 (1983) 477-491.

[6] G.M. Young, H.W. Nesbitt, The lower Gowganda Formation in the southern part of the Huronian outcrop belt, Ontario, Canada: stratigraphy, depositional environments and tectonic setting, Precambr. Res. 29 (1985) 265-301.

[7] P.S. Mustard, J.A. Donaldson, Early Proterozoic iceproximal glaciomarine deposition: the Lower Gowganda Formation at Cobalt, Ontario, Canada, Geol. Soc. Am. Bull. 98 (1987) 373-387.
[8] R.I. Harker, R. Giegengack, Brecciation of clasts in diamictites of the Gowganda formation, Ontario, Canada, Geology 17 (1989) 123-126.

[9] A.D. Miall, Sedimentation on an Early Proterozoic continental margin under glacial influence: The Gowganda formation (Huronian), Elliot Lake area, Ontario, Canada, Sedimentology 32 (1985) 763-788.

[10] G.M. Young, The Early Proterozoic Gowganda Formation, Ontario, Canada, in: M.J. Hambrey, W.B. Harland (Eds.), Earth's Pre-Pleistocene Glacial Record, Cambridge University Press, London, 1981, pp. 807-812.

[11] G.M. Young, H.W. Nesbitt, Geochemical investigation of the paleoclimatology and provenance of the Paleoproterozoic Gowganda Formation, Ontario, Canada, Geol. Soc. Am. Bull. 111 (1999) 264-274.

[12] J.P. Bradbury, W.E. Dean (Eds.), Elk Lake, Minnesota: Evidence for Rapid Climate Change in the North-Central United States, Geol. Soc. Am., Boulder, CO, SPE276, 1993, 336 pp.

[13] N. Delprat, B. Escudie, P. Guillemain, R. KronlandMartinet, P. Tchamitchian, B. Torresani, Asymptotic wavelet and Gabor analysis: Extraction of instantaneous frequencies, IEEE Trans. Inf. Theory 38 (1992) 644 664.

[14] G. Plaut, M. Ghil, R. Vautard, Interannual and interdecadal variability in 335 years of central England temperatures, Science 268 (1995) 710-713.

[15] T.C. Benner, Central England temperatures: long-term variability and teleconnections, Int. J. Climatol. 19 (1999) 391-403.

[16] J.W. Hagadorn, L.D. Stott, S. Sinha, M. Rincon, Geochemical and sedimentologic variations in inter-annually laminated sediments from Santa Monica Basin, Mar. Geol. 125 (1995) 111-131.

[17] A.R. Ochadlick Jr., H.N. Kritikos, R. Giegengack, Variations in the period of the Sun-spot cycle, Geophys. Res. Lett. 20 (1993) 1471-1474.

[18] J.D. Haigh, The impact of Solar variability on climate, Science 272 (1996) 981-984.

[19] J.A. Eddy, Some thoughts on Sun-weather relations, R. Soc. London Philos. Trans. A 330 (1990) 543-545.

[20] R.G. Currie, R.G. Vines, Evidence for Luni-Solar $M_{n}$ and Solar cycle $\mathrm{S}_{\mathrm{c}}$ signals in Australian rainfall data, Int. J. Climatol. 16 (1996) 1243-1265.

[21] R.G. Currie, Luni-Solar and Solar-cycle signals in Lake Sake varves and further experiments, Int. J. Climatol. 15 (1995) 893-917.

[22] B. Zolitschka, J.F.W. Negendank, Sedimentology, dating and paleoclimatic interpretation of a 76.3-ka record from Lago-Grande-Di-Monticchio, Southern Italy, Quat. Sci. Rev. 15 (1996) 101-112.

[23] M. Ripepe, L.T. Roberts, A.G. Fischer, ENSO and sunspot cycles in varved Eocene oil shales from image analysis, J. Sediment. Petrol. 61 (1991) 1155-1163.

[24] G.E. Williams, C.P. Sonnett, Solar signature in sedimentary cycles from the late Precambrian Elatina formation, Australia, Nature 318 (1985) 523-527. 
[25] M.E. Mann, J.M. Lees, Robust estimation of background noise and signal detection in climatic time series, Clim. Change 33 (1996) 409-445.

[26] G.B. Hughes, R. Giegengack, H.N. Kritikos, Spectral indications of unexpected contributors to atmospheric $\mathrm{CO}_{2}$ variability?, Int. J. Climatol. 19 (1999) 813-819.

[27] S. Hameed, R.G. Currie, H. LaGrone, Signals in atmospheric pressure variations from 2 to ca. 70 months: part
I, simulations by two coupled ocean-atmosphere GCM's, Int. J. Climatol. 15 (1995) 853-871.

[28] C. Appenzeller, T.F. Stocker, M. Anklin, North Atlantic oscillation dynamics recorded in Greenland ice cores, Science 282 (1998) 446-449.

[29] J.M. Lees, J. Park, Multiple-taper spectral analysis: A stand-alone C-subroutine, Comput. Geosci. 21 (1995) 199-236. 